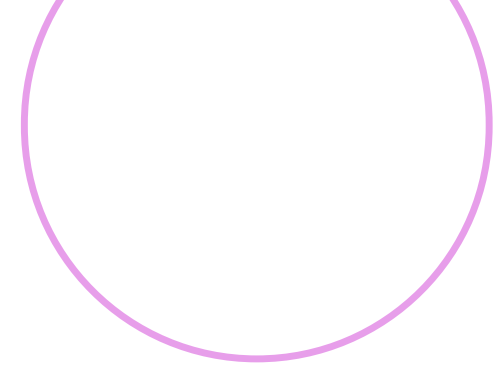

\title{
A gestão estratégica de Design de Moda como fator de sucesso da marca FARM
}

Fashion design strategic management influence in the success of the brand FARM

\section{Gabriela Costa Oliva}

Universidade do Estado de Santa Catarina - UDESC

gaboliva@gmail.com

Sandra Regina Rech

Universidade do Estado de Santa Catarina - UDESC

sandra.rech@udesc.br

Icléia Silveira

Universidade do Estado de Santa Catarina - UDESC

icleiasilveira@gmail.com

$\boldsymbol{X}$

\section{PROJËTICA}

\section{COMO CITAR ESTE ARTIGO:}

OLIVA, G. C.; RECH, S. R.; SILVEIRA, I. A gestão estratégica de design de moda como fator de sucesso da marca FARM. Projética, Londrina, v. 11, n. 1, p 134-163, 2020.

DOI: $10.5433 / 2236-2207.2020 v 11 n 1 p 134$

Submissão: 27-12-2017

Aceite: 04-06-2019

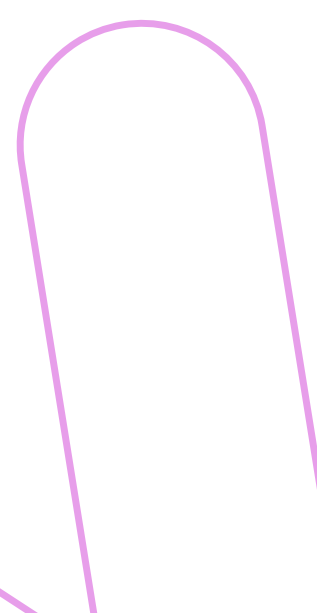




\section{A gestão estratégica de Design de Moda... marca FARM}

OLIVA, G. C.; RECH, S. R.; SILVEIRA, I.

RESUMO: Este artigo tem por objetivo apresentar os aspectos da gestão estratégica de design de moda que contribuem para o sucesso no mercado da marca de moda feminina FARM. Envolve uma abordagem sobre identidade e posicionamento da marca no desenvolvimento de produtos e foca no processo criativo e no papel do diretor criativo na organização dos conceitos e estratégias do desenvolvimento de produto de moda. Utilizou-se a pesquisa qualitativa e descritiva para atingir os objetivos propostos, desenvolvida nos limites de um estudo de caso. Para a coleta dos dados foi realizada a revisão bibliográfica assim como a entrevista subsidiada por um questionário semiestruturado. Os dados foram analisados por meio do método indutivo, por comparação entre a fundamentação teórica apresentada e os dados obtidos. Observou-se como a valorização da gestão da marca no desenvolvimento do processo criativo de seus produtos, influencia o resultado final de suas coleções e, por consequência, o sucesso mercadológico da empresa.

Palavras-chave: Gestão de marca. Design de moda. Consumo. Lifestyle. Direção criativa.

ABSTRACT: This paper aims to present the aspects of fashion design strategic management that contributed to the success of the women's fashion brand FARM. It involves an approach on brand positioning and identity in product design, focusing on the creative process and the creative direction in organizing concepts and strategies for designing fashion products. Qualitative and descriptive research methods were used to reach the objectives, through a case study. For the data collection, a bibliographic review was carried out, as well as an interview supported by a semi-structured questionnaire. Data were analyzed through the inductive method, by comparing the theoretical basis presented and the data obtained. It was observed how the valorization of the brand management along the creative process influences their final product collection and, therefore, the company marketing success.

Keywords: Brand management. Fashion design. Consumption. Lifestyle. Creative direction. 
Projética, Londrina, v.11, n.1, p. 134-163, abril 2020

\section{INTRODUÇÃO}

Esta pesquisa retrata os elementos da gestão estratégica do design de moda, especificamente a gestão de marca (branding), e sua aplicação no desenvolvimento dos produtos da marca FARM com foco no processo criativo. $O$ sucesso de uma marca de moda é resultado de uma união de esforços entre todos os departamentos da empresa. A forma como a marca coloca-se frente ao seu consumidor, como cria seus produtos, como se comunica, influencia nas vendas e na percepção da marca. A gestão estratégica do design de moda pode ser o diferencial na validação da mesma frente ao mercado.

Contudo, muitas empresas quando chegam no auge do sucesso, podem deixar de monitorar suas estratégias e de reavaliá-las não acompanhando as mudanças do mercado, o comportamento da concorrência e as preferências do seu consumidor, sem criar assim, movimento de marca e inovação. Além disso, o uso constante de relatórios de tendências e a falta de foco na identidade da marca cria um mercado uniforme, com marcas sem personalidade e criando produtos muito similares. Frente aos tipos de mudanças e de inovações que atingem os negócios de moda, as empresas podem precisar avaliar suas ações estratégicas de gestão da marca.

Diante desses problemas, esta pesquisa tem por objetivo identificar os aspectos da gestão estratégica de design de moda que contribuíram para o sucesso no mercado da marca FARM. Envolve uma abordagem sobre identidade e posicionamento da marca no desenvolvimento de produtos, incluindo a utilização da pesquisa de estilo de vida do seu consumidor como instrumento metodológico para observação e coleta de dados, usados tanto no desenvolvimento de produtos, quanto em ações da marca. Abrange também o desenvolvimento de produtos, focando no papel do diretor criativo que organiza os conceitos e estratégias do desenvolvimento dos produtos de moda. 
A justificativa da pesquisa está na relevância das ferramentas de gestão estratégica de design de moda para a sobrevivência das marcas na indústria de vestuário, cujo grau de competição, como já destacado, é cada vez maior. É importante ressaltar que a integração pelas empresas da publicidade, da administração, da arquitetura, do marketing e do design potencializa as possibilidades de diferenciação da marca, podendo torná-las únicas e desejadas. A gestão estratégica do design favorece a gestão de marca, permite a criação e o desenvolvimento de produtos, do marketing e da comunicação, sempre conectados com o mercado da moda. Inclui também, a manutenção da identidade, do posicionamento e o uso desses conceitos na direção criativa que, tem a função de gerir estrategicamente a criação e o desenvolvimento de produtos.

No presente trabalho foi utilizada a pesquisa qualitativa e descritiva para atingir os objetivos propostos, desenvolvida nos limites de um estudo de caso. Para a coleta dos dados foi realizada a revisão bibliográfica assim como a entrevista subsidiada por um questionário semiestruturado. Os dados foram analisados por meio do método indutivo, por comparação entre a fundamentação teórica apresentada e os dados obtidos. A fundamentação teórica contextualiza inicialmente a moda contemporânea e consumo de marcas.

\section{MODA E CONSUMO CONTEMPORÂNEO}

Para um entendimento do contexto atual da moda e do consumo, onde se situam as relações abordadas neste artigo, é importante o entendimento descrito neste tópico que aborda o papel da moda para o consumidor e a forma como ela é consumida atualmente, explicando brevemente o consumo de marcas.

A moda, segundo Gomes, Lopes e Alves (2016), é um fenômeno complexo e inerente ao comportamento humano que engloba aspectos sociais, culturais e de comunicação. De acordo com Michetti (2012), seu papel social na civilização 
Projética, Londrina, v.11, n.1, p. 134-163, abril 2020

ocidental surgiu no século XIX e na visão de Simmel (1995), seu início deu-se tanto como um elemento de distinção quanto de aprovação social para, aos poucos, a partir do estudo de Svendsen (2010), tornar-se uma ferramenta individual de comunicação. Sendo assim, "ultrapassa as definições de vestimenta ou adorno se tornando protagonista da inovação nos mais variados setores da indústria", como mencionado por Miranda (2017, p. 27).

Na sociedade contemporânea, em constante evolução, o homem muda o tempo todo a forma como se relaciona consigo mesmo e com o grupo. Mesmo que a moda tenha se apresentado como uma forma de distinção, conforme mencionado anteriormente, atualmente pode ser identificada como fenômeno cultural, influenciando comportamentos, produtos, arte, tecnologia, música, e outros, como abordado por Gomes, Lopes e Alves (2016). O modo como as pessoas se apresentam perante a sociedade comunica quem são e o que pretendem. “Em todas as sociedades, certas roupas comunicam alguma coisa sobre quem as usa, e isso pressupõe alguma ideia compartilhada do que devem significar" (SVENDSEN, 2010, p. 80). É uma forma de comunicação pois representa identidades além de comunicar transformações políticas, sociais, econômicas e culturais e também constrói a identidade cultural de grupos e indivíduos.

Dentro desse sistema cheio de significados, encontram-se consumidores e marcas relacionando-se e interagindo por meio de objetos que podem ser peças de vestuário ou outros tipos de bens materiais. No caso específico do vestuário, ele representa uma das primeiras formas de expressão individual identificadas pelo outro, apresentando o indivíduo antes mesmo que tenha a chance de se comunicar verbalmente. Neste contexto, destaca-se o vestuário como parte fundamental desse consumo simbólico, uma vez que as roupas são elementos de uma linguagem visual cujos sentidos são associados aos indivíduos que as usam. Isso significa que o consumo de roupas integra o processo de construção das identidades sociais e individuais. 
Segundo Miranda (2017, p. 24), as pessoas usam o ato de consumir como forma de comunicação, onde a troca vai além das mercadorias. O que é compartilhado são valores, ideais e estilos. Partindo-se deste principio, a moda, ainda que não possa ser caracterizada como uma linguagem, é utilizada pelo homem para se identificar, comunicar e também para pertencer e delimitar sua atuação dentro dos grupos sociais, desenvolvendo ao mesmo tempo identidade social e coletiva.

\section{GESTÃO DE MARCA NA MODA}

Considera-se importante para o reconhecimento do consumidor, que a marca tenha uma identidade forte, que se destaque e comunique mensagens funcionais e emocionais de forma que o consumidor possa percebê-las e desejar comprá-la.

Na visão de Kotler (1998, p. 393), uma marca é definida como um nome, termo, sinal, símbolo ou combinação dos mesmos, tendo o propósito de identificar bens ou serviços de um vendedor ou grupo de vendedores e de diferenciá-los de seus concorrentes. Já Carvalhal (2014, p. 14), explica que uma marca se manifesta em organização, história, trajetória, fama, conceito, identidade, valores e toda significação que adiciona magia e personaliza a alma desejada de um produto. Destaca a importância de valores, diferenciação, significado e personalização para as marcas e propõe que produtos tenham "almas".

Seguindo o pensamento dos autores supracitados, é possível afirmar que esses aspectos discutidos são os definidos como intangíveis como abordados por Mozota, Klöpsch e Costa (2011, p. 125), que dizem que as funções de uma marca são: 1) criar valor para os consumidores, informando sobre os atributos dos produtos; 2) gerar valor para a empresa, diferenciando o produto e tornando tangível o que é intangível. 
Projética, Londrina, v.11, n.1, p. 134-163, abril 2020

Para Kotler (2009), desde a virada do milênio, com os avanços da tecnologia, a globalização, a velocidade da comunicação e o aumento do poder do cliente, as marcas passaram a precisar oferecer valores intangíveis junto ou através de seus produtos e um novo campo de valor se abriu diante das empresas, focando suas estratégias no relacionamento com os consumidores.

As pessoas passaram a consumir para pertencer a um determinado grupo e comunicar entre si. Esse pertencimento junto ao grupo ocorre através de símbolos que o vestuário transparece, agregados a marcas e seus produtos. "Ao consumir determinada marca de moda se está consumindo simbolicamente os valores que são atribuídos a aquela roupa" (SANTOS, 2009, p. 21).

A identificação deixou de ser apenas com a peça de roupa em si e passou a ser com tudo o que ela representa e comunica a respeito de quem consome. $E$ isso é construído através da identidade da marca. Segundo Carvalhal (2014, p. 16), essas características, que são reconhecíveis pelas pessoas, são os componentes da identidade de uma marca. Estariam inscritos no seu DNA e evidenciam o seu estilo de vida, personalidade e valores. É o que reforça o significado da marca, construído por uma acumulação coerente e pertinente de escolhas e ações.

Como pode ser constatado, o consumidor passou a se apropriar da informação agregada aos produtos que obtém, como forma de se representar. Compartilhando com essa ideia, Miranda (2017, p. 34) destaca que a construção da identidade pessoal se dá mediante o uso da identidade de marca, construída a partir de uma projeção da imagem ideal, o que leva as pessoas a desejarem uma marca pois se identificam nela. 
o sucesso de uma marca de moda é resultado de uma união de esforços entre todos os departamentos da empresa. A forma como a marca coloca-se frente ao seu consumidor, como cria seus produtos, como se comunica, influencia nas vendas e na percepção da marca. A gestão estratégica do design de moda pode ser o diferencial na validação da mesma frente ao mercado. 
Projética, Londrina, v.11, n.1, p. 134-163, abril 2020

Neste contexto, a gestão de marca comunica sua identidade, faz parte da gestão de design inserida no processo criativo e nas estratégias comerciais das marcas. Não está somente relacionada com as atividades de administração da empresa ou do setor de comunicação mas de todos os departamentos da empresa, estabelecendo, assim, uma relação entre mercado, público-alvo, produto, comunicação e identidade.

Ainda neste sentido, o conceito da identidade de uma marca deve estar vivo e em constante evolução. “O DNA da marca deve ser perene, porém não imutável, tendo que ser reavaliado e/ou validado constantemente por seus stakeholders." (GOMEZ; OLHATS; PÓLO, 2011, p. 4). Assim como uma pessoa que muda e evolui com o tempo e as vivências, as marcas devem acompanhar seu público mantendo sua essência e valores, mas se modernizando constantemente a fim de não perder a identificação com seu consumidor.

\section{GESTÃO ESTRATÉGICA DE DESIGN DE MODA}

No contexto organizacional, estratégia tem um grande número de definições e este artigo utilizará a definição de Hambrick (1980), em que a estratégia é o padrão de decisões que orientam a organização em seu relacionamento com o ambiente, afetam os processos e as estruturas internas, assim como influenciam seu desempenho. Utiliza-se também o conceito de gestão estratégica de Stead e Stead (2008), que a definem como um processo contínuo que envolve os esforços dos gestores para ajustar a organização ao ambiente onde está inserida e desenvolve vantagens competitivas.

Quanto à gestão de design, Wolff (2010, p. 48) afirma que é o termo utilizado para descrever uma série de atividades de gestão ligadas ao design e a estratégia da empresa, permitindo ver e gerenciar as questões ligadas ao uso do projeto, da intenção e da criatividade como alavancas competitivas. 
Para Best (2006, p. 12), os aspectos importantes da gestão de design estão em entender os objetivos estratégicos de uma organização e como o design pode desempenhar um papel e efetivamente pôr em prática as formas, meios, ferramentas, métodos, equipes e requisitos de planejamento para atingir esses objetivos com resultados de sucesso.

Assim, ambos os conceitos, da gestão estratégica de design - também denominada design estratégico - e da gestão de design, acabam se relacionando à medida que a gestão de design aborda a utilização do design como ferramenta estratégica de gestão para as empresas. Ao tratar de uma marca de moda, levase em conta a importância da integração dos processos criativos da marca com suas estratégias comerciais, administrativas e de marketing. Integra o trabalho da empresa de forma que ela reflita sua essência e seus objetivos em todos seus processos e pontos de contato com o consumidor. Por outro lado, também se destaca a natureza da gestão estratégica como ferramenta gerencial aplicada ao design de produto, ampliando a importância da integração do mesmo com os valores e objetivos da empresa e aplicando os valores da marca em todos os aspectos de seu desenvolvimento.

Ainda que marcas de moda sejam em sua essência empresas de design de produto, o sistema da moda, por diferir da lógica e dos processos de qualquer outro tipo de empresa, faz com que seu perfil seja único e exclusivo. Pela formação diferenciada, com foco no tipo de produto e não somente no design, é importante salientar a importância da aplicação da gestão estratégica de design em empresas de moda, bem como o trabalho do diretor criativo, contextualizado a seguir.

\section{PROCESSOS CRIATIVOS E DIREÇÃO CRIATIVA NA MODA}

Em Competitive Advantage, Porter (1995, p. 36-48) descreve como uma empresa adquire "matérias-primas" e estas passam por uma "cadeia de valor" de 
Projética, Londrina, v.11, n.1, p. 134-163, abril 2020

atividades dispostas numa ordem tal que cada etapa (p. ex., design, marketing e vendas) contribui para o valor do produto ou serviço final, que chega enfim a um consumidor disposto a pagar por esse valor. $O$ autor ainda declara que as atividades de valor são as responsáveis por construir a vantagem competitiva e a forma como elas são realizadas determinará sua contribuição para suprir as necessidades do comprador (através dos produtos) e a sua diferenciação. Em termos de empresas de moda, essa cadeia de valor engloba também uma série de agentes externos à empresa, que influenciam o processo de design de produtos de moda.

No caso da moda, o produto refere-se ao design agregado pelo nível de informação de moda presente na peça de vestuário. Normalmente não se refere a um artigo único, mas a produtos de diferentes categorias complementares, integrados em uma coleção. A sua estética sempre foi um elemento de diferenciação entre marcas, pois está na base da função do mercado. Porém, mesmo marcas de mesmo estilo estético podem se diferenciar através de características de design e personalidade de marca traduzidas no produto.

Uma das grandes questões atuais, no desenvolvimento de produtos de moda, é a complexidade de todo o processo em si que engloba uma grande quantidade de fatores influenciadores.

O desafio na atualidade para produtores e designers, ao atuarem em cenários definidos como dinâmicos, fluidos, mutantes e complexos, deixa de ser definitivamente o âmbito tecnicista e linear (desafios marcantes na primeira modernidade), passando também à arena ainda desconhecida e pouco decodificada dos atributos intangíveis dos bens de produção industrial (MORAES, 2010, p. 11).

A quantidade de informações que impactam o caminho criativo, produtivo e de difusão dos produtos faz com que as roupas não sejam criadas e desenvolvidas apenas sob a ótica do estilo e da temática conceitual da coleção escolhida pela 
marca mas, ao contrário, o processo envolve desde os objetivos estratégicos e econômicos da empresa, até as tendências de moda relevantes, as inspirações, as limitações produtivas, o perfil e o acompanhamento do público alvo definido, entre outros.

Projetos de vestuário de moda, geralmente, englobam a concepção de vários artefatos em concomitância, vinculados por uma mesma ideia central. Essa essência partilhada guia os princípios funcionais/formal/visual do conjunto de artefatos projetados, respeitando a imagem da marca e as metas comerciais da empresa que propõe os novos produtos e/ou serviços. A diretriz expressa pelo conceito gerador é decodificada em elementos configurativos, guiando todo o processo projetual e ajudando a manutenção da coerência de linguagem (SANCHES, 2016, p. 72).

Assim, a criação de um produto de moda é entendida como uma tarefa extremamente complexa, elencando uma grande variedade de informações em seus processos, informações essas que não só influenciam as decisões do processo criativo, como também, de alguma forma, devem ser percebidas no produto final.

Sanches (2011) constrói visualmente a dinâmica dos agentes que influenciam e direcionam a gestão de design de moda (Figura 1), como processo tático no desenvolvimento de produtos e todas as informações que acarreta, conforme abordado anteriormente. Acentua a sua complexidade e justifica a necessidade da gestão confirmando, dentro do contexto acima descrito, as questões relativas a gestão de marca.

A partir dessa dinâmica, entende-se que o produto de moda, resultado do processo de criação e desenvolvimento, decorre da integração do conceito de coleção com questões de identidade de marca, estratégias e metas da empresa, estética, comportamento do consumidor, previsões de tendências estéticas, de 
Projética, Londrina, v.11, n.1, p. 134-163, abril 2020

comportamento e do mercado, assim como ideias relevantes no momento em que a coleção atuará no mercado. Tudo isso confere à direção criativa, um trabalho extremamente complicado e extenuante de pesquisa, integração e codificação de informações, além de conhecimento extenso do setor onde atua.

Figura 1 - Fluxo de informações entre os agentes influenciadores do design de moda

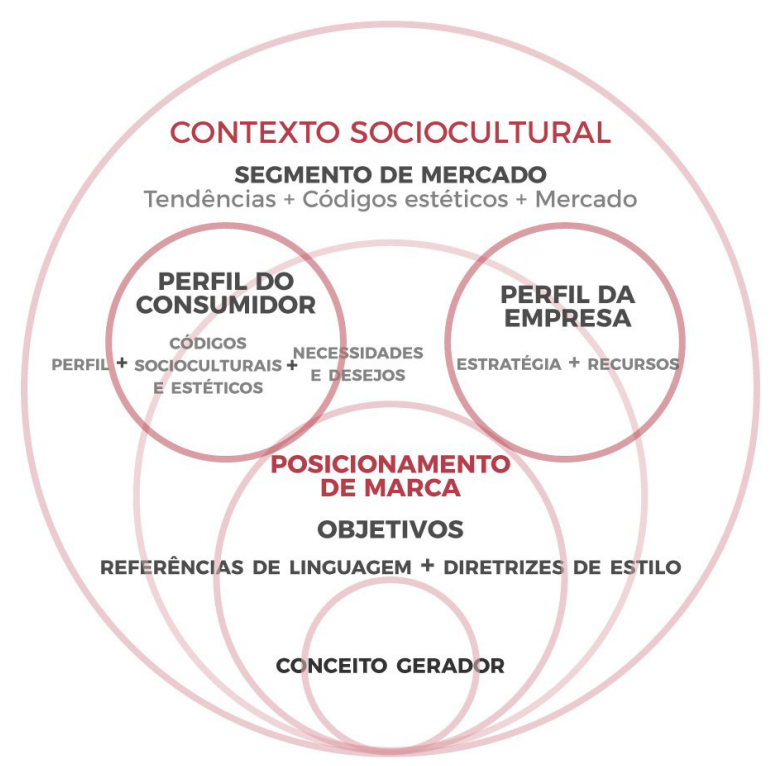

Fonte: Adaptado de Sanches (2011).

Todo esse processo, segundo Moraes (2010, p. 11), exige dos responsáveis pelo direcionamento e processo criativo, uma capacidade permanente de atualização e de gestão da complexidade.

Destaca-se, então, a relevância da gestão estratégica no processo criativo do produto e, nesse processo, a participação do diretor criativo como gestor de design. Esse profissional tem a função de integrar aspectos criativos, comerciais 
e administrativos no processo de criação de produtos. Daí a sua importância na união dos conceitos que definem o desenvolvimento de produtos e coleções de moda.

Na visão de Martins (2004), nas estruturas padronizadas por unidades organizacionais com funções distintas, atualmente o gestor possui a tarefa de conseguir equipes motivadas e integradas. Estas estruturas, ao trabalharem isoladamente, podem acabar perdendo de vista os objetivos da organização ou agindo de forma não otimizada, atendendo somente os objetivos do próprio setor. Isso significa que ainda que façam parte da mesma empresa, os departamentos raramente trabalham de forma integrada, menos ainda levando em consideração os valores, objetivos e a identidade das marcas.

Martins (2004) ainda destaca que se espera de um gestor atual, a tomada de decisões de forma fundamentada, com foco na obtenção de resultados, que seja eficaz, tenha alta probabilidade de sucesso e que assuma responsabilidades com base nos objetivos da organização.

O processo criativo de produtos de moda envolve tanto inspiração quanto pesquisa e planejamento. Normalmente, em um resumo simplificado, independente do tamanho da marca, uma coleção de produtos em seu planejamento, deverá sofrer a influência da gestão comercial, das ofertas da indústria têxtil e da administração da empresa. Em seguida, detalha-se o escopo da coleção, a quantidade e os tipos de peças (mix) a serem criadas para, na sequência, por meio das pesquisas de tendências, do contexto de consumo e do público alvo, das inspirações e das estratégias da marca, definir o conceito da coleção, montando-se a cartela de cores e definindo-se as opções de modelagens que serão utilizadas. Depois disso, são elaborados os desenhos e ideias que serão desenvolvidos, modelados, coordenados e avaliados; após uma dada quantidade será selecionada e por fim produzida. 
Projética, Londrina, v.11, n.1, p. 134-163, abril 2020

Por trás da roupa finalizada, existe um processo complexo onde o gestor de design tem papel fundamental. O profissional, conhecido como diretor criativo, tem o papel de unir as dimensões criativas e comerciais da marca, sem perder de foco os objetivos e a essência da mesma. A função possui uma série de particularidades e uma grande importância dentro do processo de desenvolvimento de produtos.

A direção criativa tem a função de ajudar a fazer a marca crescer e funcionar de forma lucrativa, influenciando em seu desenvolvimento, posicionamento e contando uma boa história através de coleções de sucesso; é também a gestão de design, a nível tático e operacional, no desenvolvimento de produtos eficazes e eficientes. Os diretores criativos são responsáveis por criar um contexto para a marca, levando a sua identidade para o desenvolvimento do produto, sua apresentação ao mercado e a comunicação da marca. Eles devem liderar criativamente a marca trabalhando lado a lado a sua gestão executiva.

O profissional que ocupa o cargo de diretor criativo dentro de uma marca de moda, necessita ter vasto entendimento de muitas áreas de conhecimento de moda, incluindo processos criativos e produtivos com uma visão global e uma grande habilidade em agregar e traduzir informações em produtos. Ele gerencia e acompanha todos os aspectos do desenvolvimento do produto, de sua criação e concepção (conceito, cor, modelagem, unidade, arte) até a produção, finalização, divulgação e as vendas, incluindo o trabalho de pesquisa, delimitação de coleção, custos, cronograma, e acompanhamento e escolha das tendências que serão utilizadas. Cabe à direção criativa não só direcionar o processo criativo como delimitar sua metodologia dando atenção às partes do processo que são decisivas na qualidade final do produto de moda e sua eficácia.

A função também engloba em seu trabalho, os objetivos administrativos da empresa, conhecimentos de identidade e de gestão de marca, assim como de seu público, acompanhamento do mercado e das vendas, marketing, desenvolvimento 
de campanhas, visual merchandising, parcerias e eventos. Supervisionando todo o processo de desenvolvimento de produtos e da apresentação da marca ao mercado, seja através das vendas ou da comunicação, percebe-se que seu papel é tão importante na criação dos produtos em si quanto na gestão da empresa.

Como observa Silva (2012), a direção criativa de moda é uma nova profissão - nascida na Europa no final dos anos oitenta - que pressupõe que o profissional deve entender de negócios e de criação e saber trabalhar juntando essas áreas e ainda usar esse conhecimento para desenvolver produtos. Dessa forma, é importante que o profissional desenvolva um processo de criação que relembre os outros profissionais envolvidos não só na temática da coleção, mas também nos objetivos comerciais da empresa, no perfil do público alvo e na identidade da marca, de forma a criar coleções concisas e eficazes. Corroborando com essa ideia, Meadows (2013, p. 69) destaca que é preciso encontrar um equilíbrio saudável entre a função criativa do designer de moda e a função do gestor comercial que vai olhar para o produto sob o ponto de vista da análise de vendas.

É importante entender o papel da direção criativa na gestão das empresas e marcas de moda, uma vez que ela garante que as equipes do processo traduzam e comuniquem os valores da marca em produtos, serviços e experiências desejáveis e viáveis. Na prática, a direção criativa representa, na moda, o nível tático da gestão de design por ser a coordenação não só do processo de desenvolvimento de produtos, como também de seu departamento criativo além de influenciar nos conceitos de comunicação e difusão dos produtos.

Cabe ao diretor criativo dar, não só direção ao processo criativo, como delimitar sua metodologia dando atenção às partes do processo que são decisivas na qualidade final do produto de moda. Dentre elas, destacam-se a pesquisa de tendências e a pesquisa de estilo de vida como diferenciais no processo de desenvolvimento de produtos com identidade de marca. 
Projética, Londrina, v.11, n.1, p. 134-163, abril 2020

\subsection{Pesquisa de Tendências e Estilo de Vida e Sua Aplicação no Processo Criativo}

Como descrito anteriormente, parte do processo criativo engloba a pesquisa de tendências, uma das etapas chave no desenvolvimento de produtos de moda que têm se tornado uma das principais indicações dos rumos que as coleções de moda costumam seguir.

Para Santos (2017, p. 23), valores socioculturais refletem o espírito do tempo (zeitgeist) fragmentado em distintas tendências de comportamento e consumo, que se revelam e se hibridizam em diferentes manifestações culturais, denunciando a alma de uma época por meio da arte, da moda, do design, da publicidade, entre outros. A pesquisa de tendências é de natureza multidisciplinar, integra diversas áreas do saber como psicologia, sociologia, antropologia, semiótica e neurociência, e investiga comportamento e consumo para entender valores sociais e antecipar manifestações de necessidades, motivações de compra e direcionar inovação.

O mercado contemporâneo conta com empresas especializadas em tendências que oferecem o serviço de pesquisa de micro e macrotendências, assim como a cobertura de todos os eventos de moda das principais capitais do mundo. Seus resultados são tabulados em indicações de modelagens, cores, temáticas, materiais, padrões e outros. Porém, diante de tanta disponibilidade de informação e em um mercado tão acirrado, é muito comum marcas perderem o foco de sua essência e personalidade na obrigação de oferecer sempre a última tendência. Em um ambiente em que outras marcas criam produtos baseados nas mesmas informações, oferecem coleções inteiras com produtos muito similares, não mostrando, assim, nenhuma diferenciação aos olhos do consumidor. "Atualmente existem produtos demais, marcas demais, barulho demais e marketing demais; logo sobreviver é um desafio" (CARVALHAL, 2014, p. 11). 


\section{A gestão estratégica de Design de Moda... marca FARM}

OLIVA, G. C.; RECH, S. R.; SILVEIRA, I.

A pesquisa de tendências por si só não é suficiente para fornecer indicações de caminhos criativos no desenvolvimento de produtos e, ainda que seja lugar comum a ideia de conhecer o seu público alvo e saber para quem os produtos estão sendo desenvolvidos, poucas são as marcas que detêm um conhecimento profundo sobre seu consumidor. Menos ainda são as marcas que fazem um trabalho de acompanhamento desse consumidor e de seu estilo de vida.

De acordo com Carvalhal (2014, p. 88), como estilo de vida pode-se entender o padrão de ação expresso por uma pessoa em suas atividades e interesses, envolvendo mais do que sua classe social ou faixa etária. É algo que está totalmente ligado a sua personalidade - relaciona-se com o que ela faz, o que gosta, como se expressa, lugares que frequenta, no que acredita e quais valores estão presentes em suas atitudes. Isso vai muito além dos fatores demográficos e geográficos indicados nas pesquisas tradicionais.

A ideia aqui não é substituir a pesquisa de tendências que, focada em comportamento e consumo, tem muita importância no desenvolvimento e sucesso de um produto de moda; mas somar à pesquisa de tendências, a pesquisa de estilo de vida. “Enquanto a pesquisa de estilo de vida, quer dar conta do desejo de grupos em determinado estilo, a de macrotendências quer identificar para onde estão indo os desejos coletivos" (SILVA, 2012, p. 8). Isso porque a pesquisa de tendências, como é conhecida, fica muito mais fácil de ser interpretada quando se tem uma noção do que dela vai atingir em seu público, em que momento e de que forma. É muito diferente de tentar agradar a todos e, com sorte, vender algum produto ou fazer o que todos estão fazendo porque é isso que se imagina que o consumidor deseja. Ser assertivo no desenvolvimento de uma coleção, sabendo o que interessa ao seu cliente, é mais eficaz para o sucesso comercial da marca.

É importante salientar que essa pesquisa não é feita apenas uma vez, não funciona como uma definição rígida; é um trabalho constante de acompanhamento 
Projética, Londrina, v.11, n.1, p. 134-163, abril 2020

do consumidor, vivenciando e atualizando seus conceitos a cada coleção. Não serve como um parâmetro estático e não é resultado necessariamente do reflexo dos gostos pessoais dos proprietários da marca, mas vive em evolução. É a personalização da marca no formato de uma pessoa que vive, muda de ideia, de gostos, tem desejos, sonhos e vontades.

Segundo os autores, personalidades não são estáticas, os indivíduos são múltiplos, perpassam diferentes grupos interagindo de muitas formas conforme o assunto ou o momento. Por isso, destaca-se a importância da identidade bem definida da marca pois, ao comunicá-la, a marca vai se conectar com os segmentos da população que se identificam de alguma forma com essa personalidade, associando-se em diferentes momentos de vida de várias pessoas. Isso significa criar um mix da identidade da marca personificada e o estilo de vida desse personagem, atraindo através dessas informações, dados que representam seu público e oferecem inputs importantes no processo de desenvolvimento de uma coleção de moda, além de criar intersecções com vários perfis de consumidor. Justifica-se, assim, a necessidade de uma gestão de design de moda eficaz, capaz de definir processos e metodologias estratégicas no desenvolvimento de produtos.

\section{ESTUDO DE CASO - FARM}

A FARM tem um histórico de aceitação e crescimento no mercado de moda, com grande atuação nacional e reconhecimento internacional. A principal razão para a sua escolha como objeto de estudo, além do seu sucesso no mercado, é a identificação de procedimentos diferenciados em sua gestão. Diante do exposto, apresenta-se a marca, suas principais características, estratégias de branding, criação e gestão de design. A empresa disponibilizou para este estudo algumas informações contidas em seu material institucional, bem como concedeu entrevista com o gerente de branding da marca, que esclarecem questões importantes para este trabalho. 


\subsection{Apresentação da Marca FARM}

A marca FARM nasceu no Rio de Janeiro, em 1997. Atualmente, tem 70 lojas próprias em 22 estados do Brasil, um e-commerce e está em processo de expansão internacional. Em 2016, foram vendidos 3,6 milhões de peças com faturamento de 425 milhões de reais e a estimativa para 2017 é de alcançar meio bilhão de reais. Ao analisar a trajetória da empresa em seus 20 anos, seus números e crescimento mostram seu indiscutível sucesso no sentido de bons resultados e êxito evidente.

A marca é focada em um público feminino jovem, entre 18 e 25 anos, das classes A e B, definidas pela empresa como "estudantes, cariocas, universitárias, descoladas, antenadas, formadoras de opinião, alto astral, menina pra casar", as "farmetes" - apelido criado pelas próprias consumidoras da marca. Para entender melhor os conceitos da marca, foram retiradas algumas palavras-chave, declaradas pela diretora criativa da marca, no vídeo de 15 anos da empresa, disponível em seu site (http://www.farmrio.com.br): feminino, delicadeza, natureza, cores, formas, estética, a roupa reflete a autêntica menina carioca, super-romântica, desejos, emoção, fazer com alma, mimos, energia boa, um mundo da FARM, Rio de Janeiro, sem perder sua essência, emocionar é a principal missão.

De acordo com a definição de público alvo da empresa, e pelo próprio apelido criado pelas consumidoras para se autodesignar, é notável a noção - discutida no referencial teórico - de consumo simbólico e apropriação de informação. As próprias consumidoras da marca associam suas identidades à identidade da marca através do consumo de seus produtos e do compartilhamento de valores, ideias e estilos que são prontamente comunicados pela marca em seu site, apresentação institucional e, também, presentes no perfil das ações realizadas pela marca e seus produtos. O enfoque na autenticidade da menina carioca propaga, igualmente, a ideia de um estilo de vida ligado à cultura local, onde a marca foi criada, bem como reforça a ideia de pertencimento. 
Projética, Londrina, v.11, n.1, p. 134-163, abril 2020

\subsection{Gestão de Marca}

De acordo com o gestor da marca, a identidade da FARM foi elaborada desde o seu nascimento pela diretora criativa. De acordo com Carvalhal (2014), os elementos construtivos de identidade presentes na FARM vêm da personalidade e infância de sua diretora criativa e se representam através da alegria, riqueza em detalhes e capricho. $\mathrm{O}$ foco está em elementos capazes de emocionar com o propósito de decorar as mulheres (grifo nosso), despertando seu lado mais bonito e feliz. Assim, atualmente, todos da equipe de criação e produção de moda da marca entendem que o produto precisa ser construído para deixar a mulher mais bonita (decorar).

Na trajetória de gerenciamento da marca, a empresa adotou, a partir de 2003, um processo profissional de construção de marca que começou com uma consultoria externa para, mais tarde, a partir de 2004, instituir o departamento de branding. Este, após três meses de pesquisa, traduziu a marca em uma pessoa, definindo os seus atributos e estruturando de forma profissional os departamentos de criação. Iniciou pelo design (estilo e estampas) e pelos projetos de arquitetura; na sequencia abordou o visual merchandising e em seguida, o marketing. A partir disso, a marca começou a estruturar profissionalmente suas comunicação e identidade e a garantir a memória e a evolução da última. Segundo Carvalhal (2014), em 2010, contratou outra consultoria externa com objetivo de organizar e documentar a identidade e a essência da marca, concluindo que o arquétipo da companheira (grifo nosso) é o que melhor explica a personalidade, o papel e a imagem da FARM junto a suas consumidoras.

O departamento de branding é dividido em duas áreas. Uma área é de pesquisa que segue tendências, arte, moda e organiza o departamento entre burocracia e agenda. A outra cuida da Quero! - linha de produtos de objetos que reforça o estilo de vida da marca - e das ações de co-branding em que a FARM lança 
produtos em parceria com outras marcas, tais como Lev, Oppa, Levis, Kibon, Adidas e Havaianas.

O co-branding não fecha projetos com todas as marcas que buscam parceria com a empresa, limita-se cuidadosamente com a exposição da marca, denominada pelo gerente de branding de blindagem. Procura trazer uma atmosfera de exclusividade para a marca, fazendo apenas ações relevantes e trabalhando com marcas coerentes com o conceito da FARM, fugindo da massificação e da popularização.

O departamento de comunicação, que é pensado como um facilitador das relações da marca com o cliente, desenvolve o blog da FARM (Adoro!), divulgando todo o trabalho de conteúdo de marca, dia-a-dia da fábrica e assuntos relacionados e relevantes para a personalidade da mesma, que se desdobra também nas redes sociais Twitter, Instagram e Facebook. Esse trabalho permite à marca comunicar-se diretamente com seus consumidores, mantendo-a conectada com o dia-a-dia e os valores de seus clientes.

O fato de a empresa ter um departamento específico de branding já demonstra uma preocupação com a gestão da marca em seus processos. "Ao entrar na empresa, os novos funcionários das áreas de criação, comercial e RH passam por um treinamento de branding com o gestor da marca, onde aprendem sobre a sua história, seu estilo de vida e significado" (CARVALHAL, 2014, p. 329), algo inexistente na grande maioria das empresas de moda. Todos os outros trabalhos desenvolvidos ou contratados pela empresa, no sentido de entender claramente o perfil da marca e utilizá-lo em todos os processos da empresa, demonstram a importância que é dada à gestão da marca e a busca por formas de evidenciar os valores e a personalidade da mesma, assim como de mantê-los vivos e em constante evolução. 
Projética, Londrina, v.11, n.1, p. 134-163, abril 2020

\subsection{Gestão de Design de Moda na FARM}

A gestão estratégica de design de moda faz-se presente por meio dos processos e metodologias de desenvolvimento de produto e da integração entre os departamentos, trabalhando de forma a agregar as estratégias organizacionais no desenvolvimento de produtos.

O departamento de branding também é responsável pela apresentação do conceito de cada coleção da FARM, que deve ser capaz de gerar muitos assuntos a serem desenvolvidos durante a coleção e, assim, manter o cliente engajado com a marca. Após ser apresentado para a empresa, ele é traduzido em símbolos e materializado em design (estampas e peças), no visual merchandising, na vitrine, nos materiais gráficos, no lançamento da coleção, na convenção, hotsite, lookbooks, modelos, beleza e comunicação. Para isso, foi criado um núcleo de profissionais que envolvem o gerente de arte (estampas), estilistas, uma modelista, uma pilotista, o departamento de branding (que funciona como um núcleo de pesquisa, dando apoio para todos os departamentos da empresa), as diretoras criativas da FARM e da Fábula (marca infantil ligada à FARM) e às vezes, também, consultorias externas de tendências. Isso demonstra o esforço em manter a identidade da marca sempre presente em seus processos e produtos. Isso vai ao encontro de Mozota, Klöpsch e Costa (2011) ao afirmarem que para criar produtos mais funcionais e eficazes, profissionais de várias áreas devem trabalhar juntos em todas as etapas de criação.

A partir do conceito da coleção, é elaborada uma ferramenta física com os prismas da coleção em cada face, que recorda os conceitos e sub-conceitos da coleção e fica disponível para lembrança de todos durante todo o tempo.

O departamento de visual merchandising utiliza o conceito de coleção no desenvolvimento da "cara" da loja. Para isso, dentro da fábrica existe uma "loja" em tamanho real, montada de acordo com o desenvolvimento da coleção, editando 


\section{A gestão estratégica de Design de Moda... marca FARM}

OLIVA, G. C.; RECH, S. R.; SILVEIRA, I.

a produção de produtos, possibilidades de apresentação e temáticas que serão trabalhadas. Essa loja é utilizada como ferramenta por todos os departamentos.

Semanalmente, ocorrem reuniões de alinhamento, de conceituação de projetos e de status de vendas, importantes para o desenvolvimento dos produtos e para a integração dos departamentos. São feitas análises de desempenho por período, por peça e ponto, gerando um histórico para as próximas coleções. A responsabilidade de unir o comercial com o conceitual é de toda a equipe; envolve a diretora criativa, o sócio da marca, o gerente de branding e todas as pessoas de cada uma das equipes, com consciência da importância de convergirem os dois aspectos.

\subsection{Processos e Direção Criativa da FARM}

A diretora criativa da marca não tinha formação em moda ou áreas relativas quando a marca começou, sua profissionalização aconteceu no decorrer do processo de desenvolvimento e crescimento da mesma. Assim, muitos dos processos da marca nasceram de forma intuitiva, valorizando aspectos que os sócios acreditavam ser importantes de acordo com suas experiências anteriores. Desde o início, houve valorização da identidade da marca e das emoções que os produtos e as experiências deveriam estimular em seus consumidores.

Além disso, o processo de desenvolvimento de coleções, como abordado anteriormente, é feito por uma equipe multidisciplinar com o uso de avaliações de vendas, de seu histórico, identidade da marca, perfil e comportamento do cliente, tendências e outros elementos. O conceito de coleção é dividido em fases: background, contexto, vontade, atmosfera, símbolos, pesquisa, personificação, cartela de cores e nome, e partes dele necessitam de informações comportamentais de seus clientes tanto quanto das tendências vigentes e seu processo de desenvolvimento dura um mês. 
Projética, Londrina, v.11, n.1, p. 134-163, abril 2020

São feitos, em média, 1.200 itens por coleção. Com grade pequena, os itens são distribuídos pelas lojas obedecendo critérios de relevância (da peça e do ponto) e de clima. Cada coleção tem várias sub-coleções (por exemplo: verão é dividido em primavera, verão, alto verão, fim de ano/ano novo, pré-carnaval e carnaval), garantindo o lançamento constante de novidades, atraindo a atenção dos clientes como um fast fashion com peças novas durante todo o tempo. As peças finais são escolhidas por votação de funcionários, assim como os preços que são definidos através de consenso da equipe, sempre focando o perfil jovem e universitário do público.

A diretora criativa põe muita ênfase no cuidado com a identidade da marca, no relacionamento com as clientes, na participação da equipe no desenvolvimento, para que as peças façam sentido para o momento que as clientes estão vivendo. Ao mesmo tempo, a visão de negócio garante, também, um cuidado com a forma como as peças serão apresentadas, onde e para quem. Fica evidente que a importância do aspecto comercial do negócio está sempre presente. Segundo a diretora criativa, em experiências anteriores, ela e seu sócio não tiveram sucesso por não oferecer às clientes aquilo que elas procuravam e hoje a marca trabalha voltada tanto para os desejos das clientes quanto os da empresa.

\subsection{Uso de pesquisa de tendências e estilo de vida e sua aplicação no processo criativo da FARM}

De acordo com o gerente de branding, a empresa entende muito do estilo de vida da marca e de suas clientes, acompanhado através de um trabalho de observação constante que facilita o desenvolvimento de ações relacionadas com o seu perfil. Esse processo também foi facilitado com a implantação do programa Eu quero FARM! Desenvolvido em novembro de 2005 e implantado de forma estruturada, o programa foi dividido em quatro etapas: identificação, diferenciação, interação e personalização da cliente. Essa estrutura teve como objetivo possibilitar 
que após o cadastramento dos clientes, fossem feitas interpretações periódicas de seu perfil e hábitos de consumo.

Através do programa, também são identificados clientes de interesse para a marca e são planejadas ações específicas para cada grupo de interesse. Dessa forma, a marca consegue saber exatamente quem são seus clientes e de que forma eles consomem e se engajam com ela, guiando o trabalho da comunicação. A experiência de seus consumidores com a marca é muito importante para a empresa.

Ainda, segundo o gestor da marca, a empresa olha muito para dentro, seu perfil, comportamento e história, antes de olhar para fora (tendências ou o que os outros estão fazendo). Isso demonstra a importância que é dada à pesquisa de estilo de vida que, junto com a pesquisa de tendências, alimenta a equipe criativa no direcionamento estético e emocional dado aos produtos da marca. A diretora criativa avaliza essa atitude quando declara que a FARM não é uma marca de roupas mas de comportamento. Para concluir, destaca-se que todos os procedimentos da gestão estratégica da marca FARM, consideram questões ligadas ao comportamento de consumo envolvendo, além dos elementos estéticos, aqueles que possam emocionar o cliente e garantir a permanência da marca no mercado.

\section{CONSIDERAÇÕES FINAIS}

O presente estudo tem como temática central, as estratégias de gestão de design de moda, focando na gestão de marca e processos criativos da marca FARM. Para guiar o estudo, foram utilizados os conceitos identificados nas estratégias da marca, apresentados no referencial teórico, e feita uma análise profunda das metodologias utilizadas pela marca de moda, utilizando informações internas da empresa e publicadas na mídia. A partir disso, é possível identificar como a 
Projética, Londrina, v.11, n.1, p. 134-163, abril 2020

valorização da gestão da marca no desenvolvimento do processo criativo de seus produtos, influencia o resultado final de suas coleções e, por consequência, o sucesso mercadológico da empresa.

Ao focar em sua identidade, acompanhar e observar o estilo de vida ligado à personalidade da marca e, ainda, integrá-los a todos os processos de todos os departamentos da empresa, tem-se em vista duas preocupações: a de reforçar sua essência em cada ponto de contato da marca com o cliente e, especialmente, com o perfil de produto apresentado; a marca se distancia do restante do mercado e garante um espaço na mente de seus consumidores.

Partindo de conceitos da gestão de marca e analisando o processo criativo da empresa, é possível identificar como seus diferenciais influenciam no desempenho da marca no mercado. O olhar atento ao comportamento do cliente cria oportunidades dentro da empresa e reforça, no mesmo, a sensação de pertencimento da marca e, juntamente com o cuidado com a identidade da marca, fortalecem sua ideia no imaginário do mercado. O seu jeito de trabalhar profissionalizou intuições vindas de experiências passadas de seus gestores, de maneira a se agregar no desenvolvimento da marca, fazendo com que ela, hoje, ocupe o espaço singular que tem no mercado. Essas estratégias, reforçadas pelos resultados econômicos positivos da empresa - mesmo diante da atual conjuntura de crise econômica do país - reforçam a possibilidade de revisão das metodologias de gestão de design de moda das marcas do mercado. 


\section{REFERÊNCIAS}

1. BEST, Kathryn. Design management: managing design strategy, process and implementation. Switzerland: AVA, 2006.

2. CARVALHAL, André. A moda imita a vida: como construir uma marca de moda. Rio de Janeiro: Estação das Letras e Cores, 2014.

3. GOMES, Nelson; LOPES, Maria Vieira; ALVES, Paulo Emanuel. Coolhunting e estudos de tendências aplicados à moda: modelo de segmentação estratégica. Moda Palavra e-periódico, Florianópolis, v. 9, n. 17, p. 5-26, jan./jun. 2016.

4. GOMEZ, Luiz Salomão Ribas Gomez; OLHATS, Magali; PÓLO, Claudia C. Fashion branding: uma relação emocional com o consumidor. ModaPalavra e-periódico, Florianópolis, v. 4, n. 8, p. 89-113, jul./dez. 2011.

5. HAMBRICK, Donald C. Operationalizing the concept of business-level strategy in research. Academy of Management Review, Briarcliff Manor, v. 5, n. 4, p. 567-575, 1980.

6. KOTLER, Philip. Administração de marcas. São Paulo: Atlas, 1998.

7. KOTLER, Philip. Marketing para o século XXI: como criar, conquistar e dominar mercados. Rio de Janeiro: Ediouro, 2009.

8. MARTINS, Rosane Fonseca de Freitas. A gestão de design como estratégia organizacional: um modelo de integração do design em organizações. 2004. Tese (Doutorado em Engenharia de Produção) - Universidade Federal de Santa Catarina, Florianópolis, 2004. 
Projética, Londrina, v.11, n.1, p. 134-163, abril 2020

9. MEADOWS, Toby. Como montar e gerenciar uma marca de moda. 2. ed. Porto Alegre: Bookman, 2013.

10. MICHETTI, Miqueli. Moda brasileira e mundialização: mercado mundial e trocas simbólicas. 2012. Tese (Doutorado em Sociologia) - Universidade Estadual de Campinas, Campinas, 2012.

11. MIRANDA, Ana Paula. Consumo de moda: a relação pessoa-objeto. 2. ed. São Paulo: Estação das Letras e Cores, 2017.

12. MORAES, Dijon. Metaprojeto: o design do Design. São Paulo: Blucher, 2010.

13. MOZOTA, Brigitte B.; KLÖPSCH, Cássia; COSTA, Filipe C. Xavier. Gestão do design: usando o design para construir valor de marca e inovação corporativa. Porto Alegre: Bookman, 2011.

14. PORTER, Michael E. Competitive advantage: creating and sustaining superior performance. New York: Free Press, 1995.

15. SANCHES, Maria Celeste de Fatima. O projeto do intangível na formação de designers de moda. 2016. Tese (Doutorado em Arquitetura e Urbanismo) Universidade de São Paulo, São Paulo, 2016.

16. SANCHES, Maria Celeste de Fatima. Uma análise da delimitação projetual no design de moda. In: CONGRESSO INTERNACIONAL DE PESQUISA EM DESIGN, 6., 2011, Lisboa. Anais [...]. Lisboa: CIAUD, 2011. v. 1, p. 1-4.

17. SANTOS, Janiene. Sobre tendências e o espírito do tempo. 2. ed. São Paulo: Estação das Letras e Cores, 2017 
18. SANTOS, S. R. Marketing de moda "EU QUERO FARM!": desvendando o sucesso por trás da FARM. 2009. Monografia (Graduação em Comunicação Social) - Universidade Federal do Rio de Janeiro, Rio de Janeiro, 2009.

19. SILVA, Aldo Clécius Neris. A pesquisa de estilo de vida como metodologia e recurso para direção criativa de moda. In: COLÓQUIO DE MODA, 8., 2012, Rio de Janeiro. Anais [...]. Rio de Janeiro: ABEPEM, 2012. Disponível em: http:// www.coloquiomoda.com.br/anais/Coloquio\%20de\%20Moda\%20-\%202012/ GT07/ARTIGO-DE-GT/103617_A_pesquisa_de_estilo_de_vida_como_metodologia_e_recurso_para_direcao_criativa_de_moda.pdf. Acesso em: 6 nov. 2017.

20. SIMMEL, Georg. A filosofia da moda. Rio de Janeiro: Zahar, 1995.

21. STEAD, Jean Garner; STEAD, W. Edward. Sustainable strategic management: an evolutionary perspective. International Journal of Sustainable Strategic Management, Genève, v. 1, n. 1, p. 62-81, 2008.

22. SVENDSEN, Lars. Moda: uma filosofia. Rio de Janeiro: Zahar, 2010.

23. WOLFF, Fabiane. Sistemática de avaliação da gestão de design. 2010. Tese (Doutorado em Engenharia de Produção) - Universidade Federal do Rio Grande do Sul, Porto Alegre, 2010.

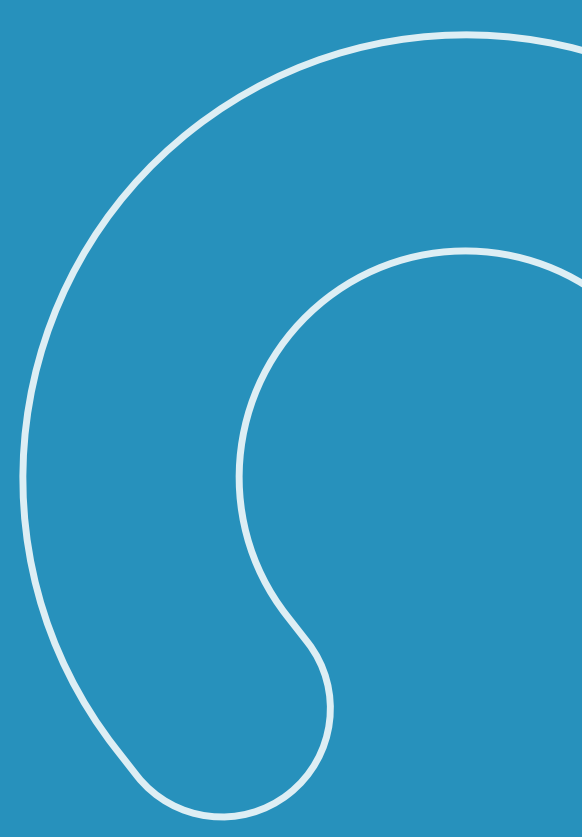

